\title{
Comprehensive mapping of local and diaspora scientists: A database and analysis of 63,951 Greek scientists
}

an open access journal

\section{Check for updates}

Citation: loannidis, J. P. A., Koutsioumpa, C., Vakka, A., Agoranos, G., Mantsiou, C., Drekolia, M. K. Avramidis, N., Contopoulos-loannidis, D. G., Drosatos, K., \& Baas, J. (2021). Comprehensive mapping of local and diaspora scientists: A database and analysis of 63,951 Greek scientists.

Quantitative Science Studies, 2(2),

733-752. https://doi.org/10.1162/qss_a 00136

DOI:

https://doi.org/10.1162/qss_a_00136

Peer Review:

https://publons.com/publon/10.1162 /qss a 00136

Received: 21 January 2021

Accepted: 24 March 2021

Corresponding Author:

John P. A. loannidis

jioannid@stanford.edu

Handling Editor:

Ludo Waltman
Copyright: @ 2021 John P. A. loannidis, Chara Koutsioumpa, Angeliki Vakka, Georgios Agoranos, Chrysanthi Mantsiou, Maria Kyriaki Drekolia, Nikos Avramidis, Despina G. Contopoulos-loannidis, Konstantinos Drosatos, and Jeroen Baas. Published under a Creative Commons

Attribution 4.0 International (CC BY 4.0) license.

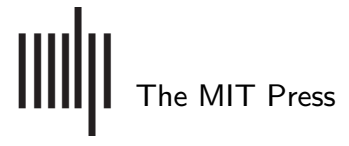

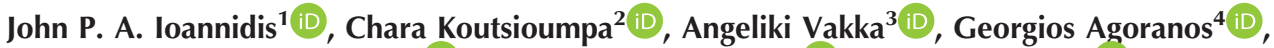 \\ Chrysanthi Mantsiou ${ }^{5}$ (D), Maria Kyriaki Drekolia ${ }^{6}$ (D), Nikos Avramidis ${ }^{7}$ iD, \\ Despina G. Contopoulos-loannidis ${ }^{8}$ (i) , Konstantinos Drosatos ${ }^{9,10}$ (iD), and Jeroen Baas ${ }^{11}$ (iD \\ ${ }^{1}$ Stanford Prevention Research Center, Department of Medicine, and Department of Epidemiology and Population Health, \\ Stanford University School of Medicine and Meta-Research Innovation Center at Stanford (METRICS), Stanford, California, USA \\ ${ }^{2}$ Department of Neurobiology, Harvard Medical School, Boston, USA \\ ${ }^{3}$ School of Medicine, University of Patras, Greece \\ ${ }^{4}$ Hellenic Center of Mental Health and Research (EKEPSYE), Athens, Greece \\ ${ }^{5}$ Clinical Research and Evidence-Based Medicine Unit, Second Medical Department, \\ Aristotle University of Thessaloniki, Thessaloniki, Greece \\ ${ }^{6}$ Institute for Vascular Signalling, Centre for Molecular Medicine, Goethe University, Frankfurt am Main, Germany \\ ${ }^{7}$ Roslin Institute, University of Edinburgh \\ ${ }^{8}$ Department of Pediatrics, Stanford University School of Medicine, Stanford, California, USA \\ ${ }^{9}$ Department of Pharmacology, Center for Translational Medicine, Lewis Katz School of Medicine, \\ Temple University, Philadelphia, PA, USA \\ ${ }^{10}$ ARISTEiA-Institute for the Advancement of Research \& Education in Arts, Sciences \& Technology, McLean, VA, USA \\ ${ }^{11}$ Elsevier, Amsterdam, Netherlands
}

Keywords: brain drain, diaspora, Greece, science mapping, scientific workforce

\begin{abstract}
Research policy and planning for a given country may benefit from reliable data on both its scientific workforce as well as the diaspora of scientists for countries with a substantial brain drain. Here we use a systematic approach using Scopus to generate a comprehensive countrylevel database of all scientists in Greece. Moreover, we expand that database to include also Greek diaspora scientists. The database that we have compiled includes 63,951 scientists who have published at least five papers indexed in Scopus. Of those, 35,116 have an affiliation in Greece. We validate the sensitivity and specificity of the database against different control sets of scientists. We also analyze the scientific disciplines of these scientists according to the Science Metrix classification (174 subfield disciplines) and provide detailed data on each of the 63,951 scientists using multiple citation indicators and a composite thereof. These analyses demonstrate differential concentrations in specific subfields for the local versus the diaspora cohorts, as well as an advantage of the diaspora cohort in terms of citation indicators, especially among top-impact researchers. The approach that we have taken can also be applied to map the scientific workforce of other countries and nations for evaluation, planning, and policy purposes.
\end{abstract}

\section{INTRODUCTION}

The construction of scientist databases can be a useful tool for evaluation, planning, and policymaking related to science. Efforts to compile national databases of scientists with performance metrics, in particular citation indices, are sometimes undertaken by research assessment authorities (Moed, 2008; Rijke, Wouters et al., 2016). Often these efforts may not be sufficiently 
inclusive. For example, they may depend on nonsystematic efforts where scientists voluntarily contribute information themselves to be included. Moreover, citation metrics are difficult to standardize, especially when they are not calculated according to the same processes for all scientists, and when differences between scientific fields are insufficiently accounted for. Importantly, for many countries, brain drain is a major challenge for their scientific workforce (Doria Arrieta, Pammolli, \& Petersen, 2017; Ioannidis, 2004; Veugelers, 2017). In these countries, planning and policy decisions would greatly benefit from mapping not only the disciplines and impact of scientists who still work in the country but also of those who have emigrated elsewhere. First-generation emigrating scientists and often even second and higher generation emigrants may often still be interested in engaging with the scientific workforce of their country of origin, thus contributing valuable expertise. Countries with strong diaspora may benefit from the skills of diaspora scientists. Scientific diaspora can be useful for both the mobile scientists (Halevi, Moed, \& Bar-Ilan, 2016; Petersen, 2018; Robinson-Garcia, Sugimoto, et al., 2019) and the countries involved at both ends, as it can constitute a modern tool of scientific diplomacy and cooperation between the two countries (Stark, Helmenstein \& Prskawetz, 1997; Wagner \& Jonkers, 2017).

Here we demonstrate how a large-scale standardized approach can be used to create an inclusive, comprehensive database of scientists in a specific nation. Moreover, we show how one can expand that database to include also scientists who have migrated to other countries. We focus our efforts on Greece and its national workforce and scientific diaspora. Greece is a country that has sustained a very strong current of brain drain over the years (Ifanti, Argyriou et al., 2014; Moris, Karachaliou, \& Kontos, 2017; Theodoropoulos, Kyridis et al., 2014; Trachana, 2013). Moreover, the country has been hit by a major economic crisis that has severely limited funding for research and development. Despite some improvements in recent years, funding remains highly suboptimal. Furthermore, scientists of Greek origin include many extremely influential scientists worldwide and past analyses suggest that there are many high-impact Greek scientists, both in Greece and abroad, who are leaders in their fields (Yurte, 2017). Moreover, such previous work has suggested that the number of Greek scientists with substantial impact is much higher proportionately than the share of Greeks in the global population (10 million in Greece and perhaps another 3 million in the diaspora) (Yurte, 2017). Mapping Greek scientists in Greece and worldwide would be a valuable resource. The availability of comprehensive science publications databases such as Scopus and the fact that many Greek first names and a large majority of Greek last names tend to be highly specific for Greek descent allow the creation of a database of scientists of Greek origin. In this paper, we describe how we have constructed such a database and how we have examined its sensitivity and specificity in validation samples. We also present descriptive data for the entire database and for comparative evaluations of Greek origin scientists who have an affiliation in Greece and for those who have an affiliation in other countries. Our work may offer a template for similar scientist-mapping efforts on other countries.

\section{METHODS}

\subsection{Eligibility Criteria}

We aimed to capture all scientists of Greek origin who have at least five published papers (articles, reviews, and conference proceedings). Eligible scientists were both those born in Greece and those born elsewhere (second or higher generation), but whose family had a Greek origin. Scientists were eligible regardless of whether they had their current main affiliation in Greece or elsewhere. We excluded scientists who had fewer than two papers published after 1950. 
The overall strategy aimed at finding typical Greek names first and then retrieving all author profiles with these names. To capture eligible scientists with an affiliation in Greece, we queried Scopus (Baas, Schotten et al., 2020) as of January 15, 2020 and identified all the last names that had at least one author ID (with any number of papers assigned) that included an affiliation in Greece. We found 70,967 names where at least one author ID has an affiliation address in Greece. One researcher manually screened all of these names to identify those that seemed to be of Greek origin, allowing for inclusion of those who might be probable, to avoid losing potentially eligible names. A second researcher then examined the manual extraction and made amendments. Eventually, 57,732 last names were retained.

We also screened manually the files of the top 100,000 most cited scientists based on a composite indicator that had been published previously (Ioannidis, Baas et al., 2019). We used three different files of the top-cited scientists, each of which captured the top 100,000 including self-citations as well as the top 100,000 excluding self-citations based on career-long data in Scopus until the end of 2017 (https://dx.doi.org/10.17632/btchxktzyw.1\#file-ad4249ac-f76f -4653-9e42-2dfebe5d9b01); based on citations received during a single calendar year (2017) (https://dx.doi.org/1 0.17632/btchxktzyw.1\#file-b9b8c85e-6914-4b1d-815e-55daefb64f5e); and based on career-long data until the end of 2018 (https://dx.doi.org/10.17632/btchxktzyw $.1 \#$ file-bade950e-3343-43e7-896b-fb2069ba3481). These three files manually yielded 1,044, 990, and 1,013 eligible authors of Greek origin, with large overlap between the three lists.

In addition, two online sources of common Greek first names (forebears.io and www .studentsoftheworld.info/penpals/stats. php?Pays=GRE) were screened manually starting from the most common ones until 86 first names were selected that were thought to be relatively specific for Greek origin people. For example, George is a common name in Greece, but it is not Greek specific (i.e., the vast majority of people with first name George are not of Greek origin). Conversely, Georgios is highly Greek specific.

At the next step, we retrieved from Scopus all author ID files with at least five papers (articles, reviews, or conference papers) where scientists had either a seemingly Greek-specific last name (any of the 57,332 last names mentioned above, or any of the last names of highly cited Greek scientists according to any of the three previously published lists) or a seemingly Greek-specific first name (any of the 86 mentioned above). Eventually, 124,656 author ID files were retrieved.

These 124,656 files were manually screened, perusing the information for each scientist, including the first name, last name, country of listed affiliation, and institution of listed affiliation that could help identify if the scientist was of Greek origin or not. The availability of all scientists who shared one of the seemingly Greek-specific names along with country information allowed us to identify whether any of these names were in fact not Greek-specific. Some last names occur identically both in Greeks and in some other nationality (e.g., Adam or Spinelli). In these cases, information on first name could help classify that individual if the first name was characteristically Greek. If the first name did not help to differentiate in this regard, the country information was used to arbitrate. The site https://forebears.io/ was consulted also in ambiguous cases, because it shows the relative frequency of surnames and names across different countries. If a scientist in a given country had a surname that appeared more frequently in Greece than in other countries, she or he was considered of Greek origin.

Of 124,656 author files, it was concluded that 62,837 were very likely Greek. We listed alphabetically by last names the 62,837 authors and recorded additional first names that seemed to be Greek specific. By screening 2,000 names at a time, it was found that relatively few new Greek-specific names were added after screening 8,000 authors and the incremental addition of eligible Greek origin authors would be limited by adding more first names. This 
process yielded 370 seemingly Greek-specific first names and we then searched Scopus for all additional author IDs with these first names that had not been already captured in the 62,837. These additional authors were then manually screened, and 1,012 were deemed (based on their name and country information) to be eligible. The resulting database, comprising 63,849 author IDs, was subjected to validation checks as described below. Additions and deletions emerging during these validation checks and a final contribution by the authors of the present study of Greek scientists they knew of but who had not been captured increased the final count by 102 to a final count of 63,951 author IDs.

The process is summarized in Figure 1.

\subsection{Validation: Sensitivity for Capturing Scientists of Greek Origin Who Are in Greece}

To evaluate the sensitivity of the compiled database in capturing scientists who work in Greece, we searched whether it had included scientists working at a university in Greece, the University of Thessaly. Scientists working in different universities and research institutions in Greece are not likely to have systematically different names, so one university is likely to provide a reasonably representative sample. We searched Google Scholar as the reference

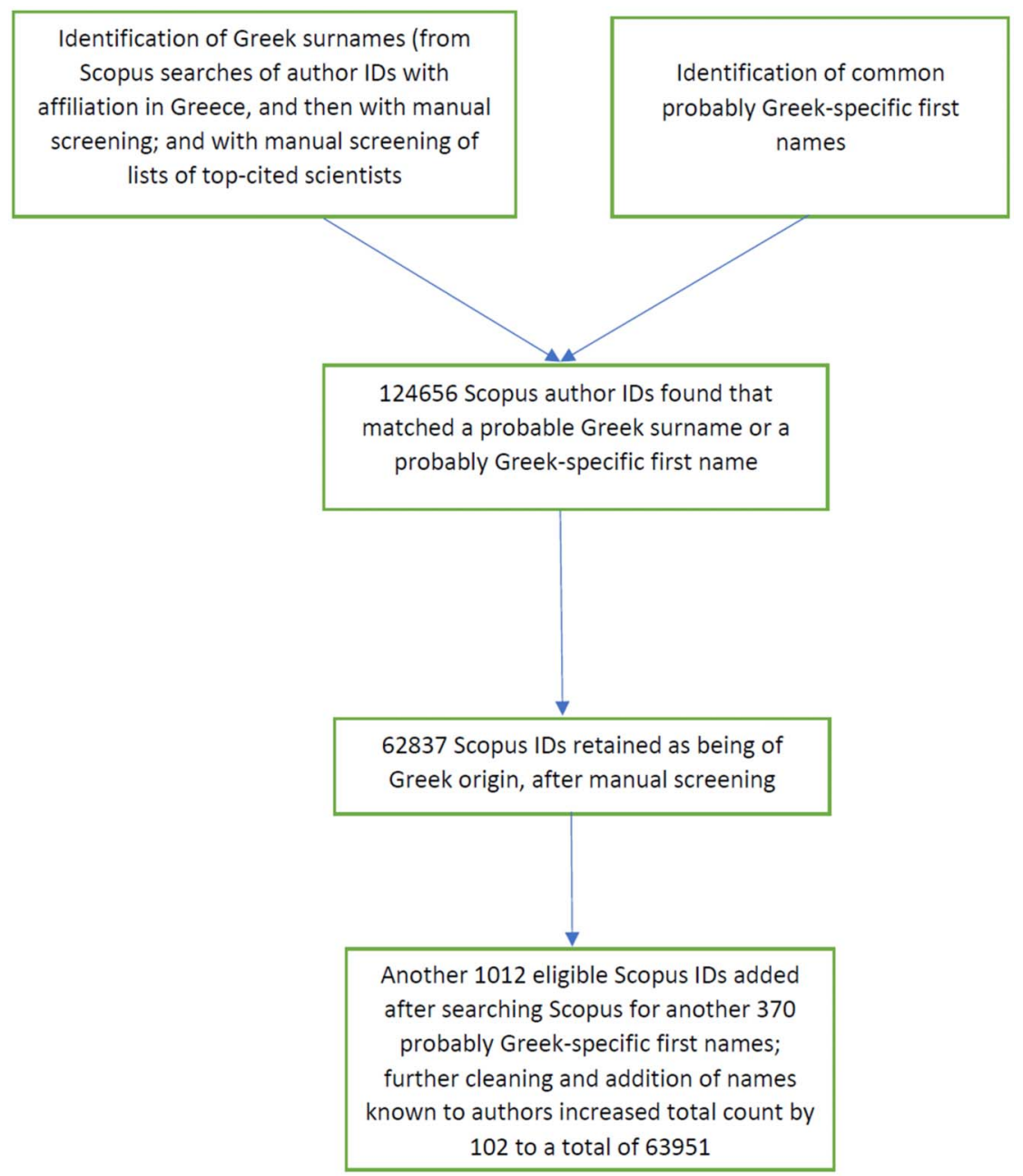

Figure 1. Flow diagram for identification of Greek scientists. 
database, as scientists need to enter their names and affiliations by themselves in creating a profile in Google Scholar. The 130 most cited scientists with profiles and University of Thessaly affiliation in Google Scholar were screened and it was found that all of them (130/130) had been included in our compiled database. Therefore, the sensitivity was $100 \%$, with binomial $95 \%$ confidence interval of $97.2 \%$ to $100 \%$.

\subsection{Validation: Sensitivity for Capturing Scientists of Greek Origin Who Are not in Greece}

To evaluate the sensitivity of the compiled database in capturing scientists of Greek origin who do not work in Greece, we used two approaches.

First, we used a sample of scientists who had entered their names in a Linkedln database of Greek biomedical scientists created by one of us (K. D.) for the World Hellenic Biomedical Association. We only considered names that had been entered by the scientists themselves, proving that they identified themselves as Greek; and we further limited the search to scientists who gave an address outside of Greece and who had a work title suggesting that they are faculty or other people in senior positions, as opposed to students. Of 42 such individuals, 34 were found to have at least five papers in Scopus. Of those 34, 26 were captured in the compiled database, for a sensitivity of $76.5 \%$ (95\% confidence interval, $58.8 \%$ to $89.3 \%$ ).

Second, we used the names of people listed in the Wikipedia entry on Greek Diaspora. These names are not necessarily of scientists; therefore we examined whether each of the names would have been captured either through one of the Greek-specific last names or through one of the first Greek-specific names that we had put together to compile our database of Greek scientists. For artists and other people who had acquired an artistic/stage name, we used their original name, as changing to artistic/stage names would not apply for scientists. We excluded from the screening people born before 1900, as Greek names in the remote past may have been different. Eventually, 28 first-generation and 88 second- or later-generation Greeks were eligible for screening. Of these 14/28 and 35/88 would have been captured by our last or first name searches, corresponding to sensitivities of 50\% (95\% confidence interval, 30.6\% to $69.4 \%$ ) and $39.8 \%$ (95\% confidence interval, $29.4 \%$ to $50.8 \%$ ), respectively.

The sensitivity estimates should be interpreted cautiously given the relatively small numbers and they leave some uncertainty about the total number of diaspora scientists.

\subsection{Validation: Specificity for Capturing Scientists of Greek Origin}

To evaluate whether the compiled database might have captured any scientists who were not actually Greek, we randomly selected 100 of the 63,849 author IDs. For each of them, we tried to find whether we could find their name written in Greek in the web. Of the 100, their Scopus affiliation was in Greece for 62, in Cyprus for four, and in other countries for 32; for two authors we had no listed affiliation in Scopus. We could find their name written in Greek for all 100 authors. Therefore, the specificity was $100 \%$ (95\% confidence interval $96.4 \%$ to $100 \%$ ).

\subsection{Evaluation of Split Author Files}

Some scientists in Scopus may have their published work split in two or more author ID files, and Scopus encourages authors to communicate directly with them to merge such split files. To assess how common this pattern might be in the compiled database of Greek authors, after listing the names alphabetically, every 600th name was selected and assessed whether more than one author ID files may exist for that person in the database. Of 106 screened names, nine $(8.5 \%, 95 \% \mathrm{Cl}, 4.0$ to $15.5 \%)$ had their work split into two files $(n=8)$ or three files $(n=1)$. 


\subsection{Data Included for Each Scientist in the Database}

From each author ID file included in the database, the following information is included based on data directly imported from Scopus on October 1, 2020 (when 7,983,030 author ID files with at least five papers (articles, reviews, or conference papers) were available in Scopus) and calculations that are the same as those performed for a recently published list of top-cited scientists (loannidis, Boyack, \& Baas, 2020): affiliation and country; publication year of earlier and latest Scopus-indexed publication; number of publications; number of publications in 1960-2020; six citation indicators (total citations, $h$-index, $h_{\mathrm{m}}$-index, citations to singleauthored publications, citations to first- or single-authored publications, citations to first-, single-, or last-authored publications) and their composite (all indicators being presented both with and without self-citations); proportion of self-citations; ratio of citations to citing papers; ranking according to the composite indicator among all scientists worldwide with at least five papers; most common field of publications according to the 22-field Science Metrix classification; two most common subfields of publications according to the 174-subfield Science Metrix classification; and ranking according to the composite indicator among all the scientists in the same main (most common) Science Metrix subfield. For details on the Science Metrix classification see Archambault, Beauchesne, and Caruso (2011) and Zhang, Zhao, and LeCun (2015). For authors where Scopus listed an affiliation but not a country, we tried to identify the country whenever it would be unambiguous based on the provided affiliation.

\section{RESULTS}

\subsection{Main Descriptive Characteristics}

Of the 63,951 author ID files included in the final database, country of affiliation was available for 63,174 , and 35,116 (55.6\%) of them had their affiliation in Greece. Large shares of this cohort

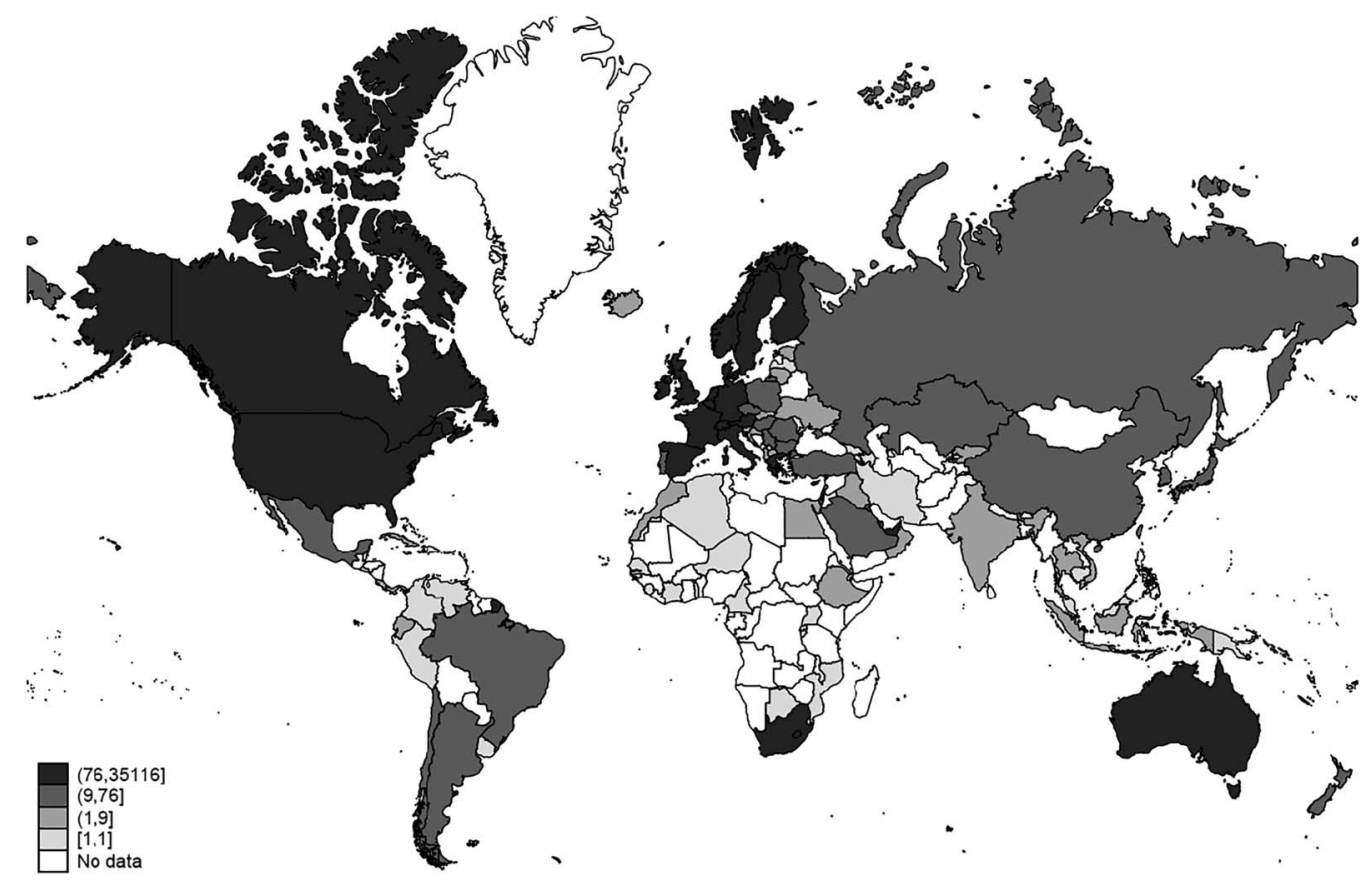

Figure 2. Worldwide distribution of scientists. 
of scientists were also located in the United States $(n=9,339,14.8 \%)$, United Kingdom $(n=$ $6,165,9.8 \%)$, Germany $(n=2,083,3.3 \%)$, Cyprus $(n=1,688,2.7 \%)$, Australia $(n=1,155$, $1.8 \%)$, France $(n=1,141,1.8 \%)$, Canada $(n=1,110,1.8 \%)$, and Switzerland $(n=994$, $1.6 \%$ ), but the diaspora was worldwide (Figure 2).

A total of $12,299(19.2 \%)$ scientists had published their first Scopus-indexed paper after 2010 and 38,248 (59.8\%) had been recently active, publishing their last paper in 2018 or later. The median number of published papers was 13 (interquartile range 8 to 31) and the median number of citations was 153 (interquartile range 52 to 478).

As shown in Table 1, scientists with affiliation in Greece had a similar number of papers to scientists with affiliation outside of Greece, but they had substantially fewer citations and fewer papers that cited their work, and were placed on average in lower ranks compared with scientists with affiliation outside of Greece. The results were qualitatively similar regardless of whether self-citations were counted or excluded (Table 1). Scientists with affiliation outside of Greece tended to have younger publication ages (median for year of first publication 2004 versus 2002).

A total of 33,956 scientists with affiliation in Greece and 26,150 scientists with affiliation in other countries could be assigned to a main scientific subfield. Among scientists who were in the top $0.1 \%$ of their subfield, the vast majority $(86 \%)$ of them had an affiliation outside of Greece rather than in Greece (96 versus 15). For the top $0.5 \%$, the respective numbers were 348 versus 89 , for the top $1 \%$ the respective numbers were 648 versus 250 , and for the top $5 \%$ the respective numbers were 2,438 versus 1,724 , always with a strong preponderance of

Table 1. Characteristics of scientists according to their country of current affiliation

\begin{tabular}{lcc}
\hline Characteristic, median (IQR) & $\begin{array}{c}\text { Affiliation in Greece } \\
n=35,116\end{array}$ & $\begin{array}{c}\text { Affiliation in other } \\
\text { country } n=28,058\end{array}$ \\
\hline Number of papers & $13(7-30)$ & $14(8-32)$ \\
Year of first paper & $2002(1993-2008)$ & $2004(1994-2010)$ \\
Year of most recent paper & $2019(2013-2020)$ & $2019(2014-2020)$ \\
$\begin{array}{l}\text { Ranking across all science, } \quad 3,505(1,691-5,463) \\
\quad \text { thousands (excluding self-citations) }\end{array}$ & $139(50-408)$ & $2,812(1,265-4,730)$ \\
Citations (excluding self-citations) & $131(48-375)$ & $184(59-609)$ \\
Citing papers (excluding self-citations) & $1.04(1.00-1.11)$ & $169(55-541)$ \\
Citations to citing papers ratio (excluding self-citations) & $14(7-25)$ & $1.07(1.02-1.16)$ \\
Percentage of self-citations & $3,508(1,681-5,458)$ & $2,801(1,259-4,697)$ \\
Ranking across all science, thousands (with self-citations) & $169(63-486)$ & $226(76-730)$ \\
Citations (with self-citations) & $28,711(11,338-61,183)$ & $21,378(7,500-48,629)$ \\
Ranking in main subfield (with self-citations) & $28,693(11,312-61,180)$ & $21,324(7,535-48,751)$ \\
Ranking in main subfield (without self-citations) & $46(22-71)$ & $37(16-61)$ \\
Percentile in main subfield (with self-citations) & $46(22-71)$ & $37(16-61)$ \\
Percentile in main subfield (without self-citations) & &
\end{tabular}


Table 2. Number of scientists in each scientific subfield

\begin{tabular}{|c|c|c|c|c|}
\hline \multirow[b]{2}{*}{ Scientific subfield } & \multicolumn{4}{|c|}{ Country } \\
\hline & Greece & Other & Unknown & Total \\
\hline Accounting & 20 & 32 & 0 & 52 \\
\hline Acoustics & 112 & 154 & 0 & 266 \\
\hline Aerospace \& Aeronautics & 57 & 159 & 3 & 219 \\
\hline Agricultural Economics \& Policy & 30 & 27 & 0 & 57 \\
\hline Agronomy \& Agriculture & 211 & 54 & 0 & 265 \\
\hline Allergy & 80 & 62 & 0 & 142 \\
\hline Analytical Chemistry & 368 & 194 & 2 & 564 \\
\hline Anatomy \& Morphology & 35 & 17 & 0 & 52 \\
\hline Anesthesiology & 130 & 81 & 0 & 211 \\
\hline Anthropology & 16 & 40 & 0 & 56 \\
\hline Applied Ethics & 7 & 18 & 1 & 26 \\
\hline Applied Mathematics & 160 & 100 & 1 & 261 \\
\hline Applied Physics & 632 & 586 & 0 & 1,218 \\
\hline Archaeology & 107 & 61 & 0 & 168 \\
\hline Architecture & 5 & 7 & 0 & 12 \\
\hline Art Practice, History \& Theory & 1 & 6 & 0 & 7 \\
\hline Arthritis \& Rheumatology & 194 & 126 & 0 & 320 \\
\hline Artificial Intelligence \& Image Processing & 1,685 & 1,293 & 7 & 2,985 \\
\hline Astronomy \& Astrophysics & 166 & 246 & 1 & 413 \\
\hline Automobile Design \& Engineering & 1 & 5 & 1 & 7 \\
\hline Behavioral Science \& Comparative Psychology & 6 & 20 & 0 & 26 \\
\hline Biochemistry \& Molecular Biology & 286 & 474 & 0 & 760 \\
\hline Bioinformatics & 72 & 105 & 0 & 177 \\
\hline Biomedical Engineering & 262 & 248 & 1 & 511 \\
\hline Biophysics & 64 & 71 & 0 & 135 \\
\hline Biotechnology & 181 & 128 & 0 & 309 \\
\hline Building \& Construction & 168 & 148 & 0 & 316 \\
\hline Business \& Management & 200 & 203 & 0 & 403 \\
\hline Cardiovascular System \& Hematology & 1,671 & 768 & 10 & 2,449 \\
\hline Chemical Engineering & 220 & 236 & 0 & 456 \\
\hline Chemical Physics & 200 & 234 & 1 & 435 \\
\hline
\end{tabular}


Table 2. (continued)

\begin{tabular}{|c|c|c|c|c|}
\hline \multirow[b]{2}{*}{ Scientific subfield } & \multicolumn{4}{|c|}{ Country } \\
\hline & Greece & Other & Unknown & Total \\
\hline Civil Engineering & 249 & 251 & 2 & 502 \\
\hline Classics & 39 & 49 & 1 & 89 \\
\hline Clinical Psychology & 24 & 51 & 0 & 75 \\
\hline Communication \& Media Studies & 9 & 56 & 0 & 65 \\
\hline Complementary \& Alternative Medicine & 6 & 8 & 0 & 14 \\
\hline Computation Theory \& Mathematics & 123 & 119 & 1 & 243 \\
\hline Computer Hardware \& Architecture & 173 & 164 & 0 & 337 \\
\hline Criminology & 7 & 45 & 0 & 52 \\
\hline Cultural Studies & 0 & 11 & 0 & 11 \\
\hline Dairy \& Animal Science & 214 & 54 & 0 & 268 \\
\hline Demography & 13 & 10 & 0 & 23 \\
\hline Dentistry & 421 & 287 & 5 & 713 \\
\hline Dermatology \& Venereal Diseases & 209 & 150 & 1 & 360 \\
\hline Design Practice \& Management & 24 & 35 & 0 & 59 \\
\hline Development Studies & 3 & 13 & 0 & 16 \\
\hline Developmental \& Child Psychology & 35 & 94 & 0 & 129 \\
\hline Developmental Biology & 172 & 712 & 0 & 884 \\
\hline Distributed Computing & 64 & 94 & 0 & 158 \\
\hline Drama \& Theater & 3 & 2 & 0 & 5 \\
\hline Ecology & 119 & 72 & 1 & 192 \\
\hline Econometrics & 8 & 13 & 0 & 21 \\
\hline Economic Theory & 4 & 22 & 0 & 26 \\
\hline Economics & 310 & 286 & 0 & 596 \\
\hline Education & 456 & 329 & 0 & 785 \\
\hline Electrical \& Electronic Engineering & 293 & 267 & 0 & 560 \\
\hline Emergency \& Critical Care Medicine & 183 & 93 & 0 & 276 \\
\hline Endocrinology \& Metabolism & 577 & 342 & 9 & 928 \\
\hline Energy & 869 & 591 & 7 & 1,467 \\
\hline Entomology & 195 & 48 & 0 & 243 \\
\hline Environmental \& Occupational Health & 14 & 25 & 0 & 39 \\
\hline Environmental Engineering & 246 & 119 & 1 & 366 \\
\hline
\end{tabular}


Table 2. (continued)

\begin{tabular}{|c|c|c|c|c|}
\hline \multirow[b]{2}{*}{ Scientific subfield } & \multicolumn{4}{|c|}{ Country } \\
\hline & Greece & Other & Unknown & Total \\
\hline Environmental Sciences & 534 & 163 & 0 & 697 \\
\hline Epidemiology & 43 & 30 & 0 & 73 \\
\hline Evolutionary Biology & 64 & 57 & 0 & 121 \\
\hline Experimental Psychology & 39 & 138 & 1 & 178 \\
\hline Family Studies & 4 & 3 & 0 & 7 \\
\hline Finance & 95 & 159 & 0 & 254 \\
\hline Fisheries & 146 & 47 & 0 & 193 \\
\hline Fluids \& Plasmas & 159 & 195 & 0 & 354 \\
\hline Folklore & 2 & 0 & 0 & 2 \\
\hline Food Science & 377 & 132 & 4 & 513 \\
\hline Forestry & 80 & 44 & 0 & 124 \\
\hline Gastroenterology \& Hepatology & 661 & 252 & 2 & 915 \\
\hline Gender Studies & 5 & 7 & 0 & 12 \\
\hline General \& Internal Medicine & 375 & 231 & 5 & 611 \\
\hline General Chemistry & 12 & 51 & 0 & 63 \\
\hline General Clinical Medicine & 102 & 38 & 0 & 140 \\
\hline General Mathematics & 237 & 162 & 0 & 399 \\
\hline General Physics & 131 & 151 & 0 & 282 \\
\hline General Psychology \& Cognitive Sciences & 2 & 5 & 0 & 7 \\
\hline Genetics \& Heredity & 96 & 174 & 0 & 270 \\
\hline Geochemistry \& Geophysics & 270 & 167 & 8 & 445 \\
\hline Geography & 37 & 26 & 0 & 63 \\
\hline Geological \& Geomatics Engineering & 272 & 187 & 1 & 460 \\
\hline Geology & 27 & 20 & 0 & 47 \\
\hline Geriatrics & 26 & 32 & 0 & 58 \\
\hline Gerontology & 17 & 17 & 0 & 34 \\
\hline Health Policy \& Services & 46 & 78 & 0 & 124 \\
\hline History & 19 & 39 & 1 & 59 \\
\hline History of Science, Technology \& Medicine & 18 & 4 & 0 & 22 \\
\hline History of Social Sciences & 2 & 7 & 0 & c \\
\hline Horticulture & 35 & 6 & 0 & 41 \\
\hline
\end{tabular}


Table 2. (continued)

\begin{tabular}{|c|c|c|c|c|}
\hline \multirow[b]{2}{*}{ Scientific subfield } & \multicolumn{4}{|c|}{ Country } \\
\hline & Greece & Other & Unknown & Total \\
\hline Human Factors & 28 & 77 & 0 & 105 \\
\hline Immunology & 706 & 487 & 1 & 1,194 \\
\hline Industrial Engineering \& Automation & 332 & 390 & 0 & 722 \\
\hline Industrial Relations & 10 & 14 & 0 & 24 \\
\hline Information \& Library Sciences & 38 & 34 & 1 & 73 \\
\hline Information Systems & 143 & 204 & 4 & 351 \\
\hline Inorganic \& Nuclear Chemistry & 250 & 128 & 1 & 379 \\
\hline International Relations & 16 & 49 & 0 & 65 \\
\hline Languages \& Linguistics & 57 & 57 & 0 & 114 \\
\hline Law & 12 & 82 & 2 & 96 \\
\hline Legal \& Forensic Medicine & 30 & 23 & 0 & 53 \\
\hline Literary Studies & 12 & 27 & 0 & 39 \\
\hline Logistics \& Transportation & 173 & 155 & 1 & 329 \\
\hline Marine Biology \& Hydrobiology & 247 & 83 & 1 & 331 \\
\hline Marketing & 56 & 75 & 0 & 131 \\
\hline Materials & 390 & 280 & 1 & 671 \\
\hline Mathematical Physics & 38 & 26 & 0 & 64 \\
\hline Mechanical Engineering \& Transports & 253 & 218 & 1 & 472 \\
\hline Medical Informatics & 184 & 78 & 0 & 262 \\
\hline Medicinal \& Biomolecular Chemistry & 236 & 149 & 0 & 385 \\
\hline Meteorology \& Atmospheric Sciences & 306 & 223 & 0 & 529 \\
\hline Microbiology & 896 & 367 & 4 & 1,267 \\
\hline Microscopy & 6 & 4 & 0 & 10 \\
\hline Mining \& Metallurgy & 50 & 28 & 2 & 80 \\
\hline Music & 6 & 13 & 0 & 19 \\
\hline Mycology \& Parasitology & 56 & 38 & 1 & 95 \\
\hline Nanoscience \& Nanotechnology & 75 & 134 & 0 & 209 \\
\hline Networking \& Telecommunications & 1,100 & 953 & 10 & 2,063 \\
\hline Neurology \& Neurosurgery & 742 & 962 & 3 & 1,707 \\
\hline Nuclear \& Particle Physics & 509 & 623 & 0 & 1,132 \\
\hline Nuclear Medicine \& Medical Imaging & 575 & 377 & 1 & 953 \\
\hline
\end{tabular}


Table 2. (continued)

\begin{tabular}{|c|c|c|c|c|}
\hline \multirow[b]{2}{*}{ Scientific subfield } & \multicolumn{4}{|c|}{ Country } \\
\hline & Greece & Other & Unknown & Total \\
\hline Numerical \& Computational Mathematics & 92 & 51 & 0 & 143 \\
\hline Nursing & 147 & 89 & 1 & 237 \\
\hline Nutrition \& Dietetics & 230 & 126 & 0 & 356 \\
\hline Obstetrics \& Reproductive Medicine & 636 & 303 & 1 & 940 \\
\hline Oceanography & 102 & 43 & 0 & 145 \\
\hline Oncology \& Carcinogenesis & 1,718 & 868 & 3 & 2,589 \\
\hline Operations Research & 138 & 118 & 0 & 256 \\
\hline Ophthalmology \& Optometry & 301 & 308 & 0 & 609 \\
\hline Optics & 74 & 155 & 0 & 229 \\
\hline Optoelectronics \& Photonics & 258 & 319 & 1 & 578 \\
\hline Organic Chemistry & 232 & 212 & 0 & 444 \\
\hline Ornithology & 17 & 4 & 0 & 21 \\
\hline Orthopedics & 461 & 348 & 1 & 810 \\
\hline Otorhinolaryngology & 206 & 128 & 0 & 334 \\
\hline Paleontology & 54 & 34 & 0 & 88 \\
\hline Pathology & 123 & 70 & 1 & 194 \\
\hline Pediatrics & 226 & 113 & 2 & 341 \\
\hline Pharmacology \& Pharmacy & 396 & 208 & 0 & 604 \\
\hline Philosophy & 12 & 44 & 2 & 58 \\
\hline Physical Chemistry & 172 & 86 & 4 & 262 \\
\hline Physiology & 26 & 59 & 0 & 85 \\
\hline Plant Biology \& Botany & 498 & 161 & 0 & 659 \\
\hline Political Science \& Public Administration & 55 & 107 & 0 & 162 \\
\hline Polymers & 282 & 222 & 1 & 505 \\
\hline Psychiatry & 277 & 265 & 2 & 544 \\
\hline Psychoanalysis & 7 & 21 & 3 & 31 \\
\hline Public Health & 87 & 139 & 0 & 226 \\
\hline Rehabilitation & 36 & 68 & 0 & 104 \\
\hline Religions \& Theology & 7 & 17 & 0 & 24 \\
\hline Respiratory System & 534 & 255 & 1 & 790 \\
\hline Science Studies & 22 & 29 & 0 & 51 \\
\hline
\end{tabular}


Table 2. (continued)

\begin{tabular}{|c|c|c|c|c|}
\hline \multirow[b]{2}{*}{ Scientific subfield } & \multicolumn{4}{|c|}{ Country } \\
\hline & $\overline{\text { Greece }}$ & Other & Unknown & Total \\
\hline Social Psychology & 30 & 74 & 1 & 105 \\
\hline Social Sciences Methods & 4 & 12 & 0 & 16 \\
\hline Social Work & 5 & 21 & 0 & 26 \\
\hline Sociology & 12 & 18 & 0 & 30 \\
\hline Software Engineering & 66 & 126 & 0 & 192 \\
\hline Speech-Language Pathology \& Audiology & 37 & 66 & 0 & 103 \\
\hline Sport Sciences & 331 & 104 & 0 & 435 \\
\hline Sport, Leisure \& Tourism & 44 & 75 & 0 & 119 \\
\hline Statistics \& Probability & 144 & 132 & 0 & 276 \\
\hline Strategic, Defence \& Security Studies & 160 & 98 & 1 & 259 \\
\hline Substance Abuse & 18 & 36 & 0 & 54 \\
\hline Surgery & 760 & 493 & 16 & 1,269 \\
\hline Toxicology & 114 & 81 & 1 & 196 \\
\hline Tropical Medicine & 34 & 32 & 0 & 66 \\
\hline Urban \& Regional Planning & 66 & 51 & 0 & 117 \\
\hline Urology \& Nephrology & 549 & 223 & 1 & 773 \\
\hline Veterinary Sciences & 164 & 71 & 2 & 237 \\
\hline Virology & 85 & 154 & 1 & 240 \\
\hline Zoology & 33 & 18 & 0 & 51 \\
\hline
\end{tabular}

scientists who were not in Greece $(79 \%, 72 \%$, and $59 \%$, respectively, for these three thresholds). Below the top $5 \%$, there was more equilibrium between scientists with affiliation outside of Greece versus in Greece, with the respective numbers being 7,842 versus 7,807 for the top $20 \%$.

\subsection{Scientific Fields}

As shown in Table 2, Greek scientists had different representation across the 174 main scientific subfields of the Science Metrix classification. A number of fields of clinical medicine, biology, and agriculture/fisheries/forestry are more heavily represented for scientists who are in Greece, while the diaspora is more prominently represented in several social and economic sciences and some cutting-edge biomedical fields. For 25 subfields, scientists in Greece exceeded by more than 2:1 scientists with affiliation outside of Greece (Anatomy \& Morphology, Environmental Engineering, Respiratory System, Obstetrics \& Reproductive Medicine, Cardiovascular System \& Hematology, Veterinary Sciences, Medical Informatics, Oceanography, Microbiology, Urology \& Nephrology, Gastroenterology \& Hepatology, General Clinical Medicine, Food Science, Marine Biology \& Hydrobiology, Plant Biology \& 
Table 3. Scientists who are among the top 15 of their scientific subfield according to a composite citation indicator, excluding self-citations

\begin{tabular}{|c|c|c|c|c|c|c|}
\hline Name of scientist & Affiliation & Country & Subfield & Rank* & $\boldsymbol{n}$ in subfield** & First degree \\
\hline Santamouris, Mattheos & $\begin{array}{l}\text { University of New South Wales } \\
\text { (UNSW) Australia }\end{array}$ & aus & Building \& Construction & 1 & 27299 & U Patras \\
\hline Peppas, Nicholas A. & The University of Texas at Austin & usa & Pharmacology \& Pharmacy & 1 & 95625 & NTUA \\
\hline Terzopoulos, Demetri & University of California, Los Angeles & usa & Software Engineering & 1 & 21515 & McGill \\
\hline Nicolaides, Kypros H. & King's College Hospital & gbr & $\begin{array}{l}\text { Obstetrics \& Reproductive } \\
\text { Medicine }\end{array}$ & 2 & 66792 & King's College \\
\hline Papadimitriou, Christos $\mathrm{H}$. & $\begin{array}{l}\text { Columbia University in the City of } \\
\text { New York }\end{array}$ & usa & $\begin{array}{l}\text { Computation Theory \& } \\
\text { Mathematics }\end{array}$ & 2 & 16762 & NTUA \\
\hline Ioannidis, John P. A. & Stanford University School of Medicine & usa & General \& Internal Medicine & 2 & 107698 & U Athens \\
\hline Stamatakis, Alexandros & Karlsruhe Institute of Technology & deu & Bioinformatics & 3 & 18635 & TU Munich \\
\hline Joannopoulos, John & Massachusetts Institute of Technology & usa & Optoelectronics \& Photonics & 3 & 102335 & UC Berkeley \\
\hline Alivisatos, A. Paul & University of California, Berkeley & usa & $\begin{array}{l}\text { Nanoscience \& } \\
\text { Nanotechnology }\end{array}$ & 4 & 75646 & U Chicago \\
\hline Ntziachristos, Vasilis & $\begin{array}{l}\text { Helmholtz Center Munich } \\
\text { German Research Center for } \\
\text { Environmental Health }\end{array}$ & deu & $\begin{array}{l}\text { Nuclear Medicine \& } \\
\text { Medical Imaging }\end{array}$ & 5 & 84992 & Aristotle U \\
\hline Guibas, Leonidas J. & Stanford University & usa & Software Engineering & 5 & 21515 & CalTech \\
\hline Buhalis, Dimitrios & Bournemouth University & gbr & Sport, Leisure \& Tourism & 6 & 6295 & U Aegean \\
\hline Giannelis, Emmanuel & Cornell University & usa & Polymers & 6 & 81179 & $\cup$ Athens \\
\hline Kanatzidis, Mercouri G. & Northwestern University & usa & Materials & 6 & 180221 & Aristotle U \\
\hline Simopoulos, Artemis P. & $\begin{array}{l}\text { Center for Nutrition, Genetics } \\
\text { \& Health }\end{array}$ & usa & Nutrition \& Dietetics & 8 & 35890 & $\begin{array}{l}\text { Barnard } \\
\text { College }\end{array}$ \\
\hline Bertsekas, Dimitri & Arizona State University & usa & Operations Research & 9 & 23674 & NTUA \\
\hline Pavlou, Paul & C. T. Bauer College of Business & usa & Information Systems & 9 & 16831 & Rice U \\
\hline Stephanopoulos, Gregory & Massachusetts Institute of Technology & usa & Biotechnology & 9 & 50679 & NTUA \\
\hline Nicolaou, K. C. & Rice University & usa & Organic Chemistry & 9 & 112004 & U London \\
\hline $\begin{array}{l}\text { Diamantopoulos, } \\
\text { Adamantios }\end{array}$ & Universitat Wien & aut & Marketing & 10 & 10516 & Heriot-Watt U \\
\hline Gazetas, G. & $\begin{array}{l}\text { National Technical University } \\
\text { of Athens }\end{array}$ & grc & $\begin{array}{l}\text { Strategic, Defence \& } \\
\quad \text { Security Studies }\end{array}$ & 10 & 17396 & NTUA \\
\hline
\end{tabular}


Antonarakis, Stylianos E. Université de Genève Faculté de Médecine

Pratsinis, Sotiris E.

Chrousos, George P.

Kalogirou, Soteris A.

Yannakakis, Mihalis

Avouris, Phaedon

Lyketsos, Constantine G.

Argyropoulos, Dimitris S.

Giannakis, Georgios B.

Davatzikos, Christos

University of Pennsylvania

National and Kapodistrian University of Athens

Cyprus University of Technology

Columbia University in the City of New York

IBM Thomas J. Watson Research Center Johns Hopkins Bayview Medical Center

NC State University

University of Minnesota Twin Cities

Brown University che

Genetics \& Heredity

11

32809

$\cup$ Athens

che

Chemical Engineering

12

56292

Aristotle $U$

grc Endocrinology \&

69452

$U$ Athens

Metabolism

cyp Energy

13

188556

Higher

Tech Inst

$\begin{array}{lllll}\text { usa } & \text { Computation Theory \& } & 13 & 16762 & \text { NTUA }\end{array}$

Mathematics

13226884 Aristotle U

usa Applied Physics

Geriatrics

Forestry

Networking \&

Telecommunications

usa

Nuclear Medicine \& Medical Imaging

Applied Mathematics

15

13

9246

Northwestern

14

24339

U London

14

162693

NTUA

84992

NTUA

usa

* Rank among all scientists in the same subfield, regardless of whether they are alive or deceased. For example, in General \& Internal Medicine the top ranked scientist is Douglas Altman who is deceased. Also of note, the top 32 scientists who are highly ranked based on the percentile in their subfield (not shown here) include 23 of the 32 who are top-ranked based on the absolute threshold (top 15 in the subfield).

** Number of scientists in the same subfield, including both those who are alive and those who are deceased; it is not straightforward to identify how many are deceased. The count includes those who have at least five papers (articles, reviews, or conference proceedings) indexed in Scopus and who have some papers classified in one of the 174 Science Metrix subfields. 
Botany, Fisheries, Sport Sciences, Environmental Sciences, Agronomy \& Agriculture, Dairy \& Animal Science, Entomology, Ornithology, History of Science, Technology \& Medicine, Horticulture, Folklore). Conversely, in 32 subfields, scientists outside of Greece exceeded by more than 2: 1 scientists with affiliation in Greece (Cultural Studies, Law, Criminology, Communication \& Media Studies, Art Practice, History \& Theory, Economic Theory, Automobile Design \& Engineering, Development Studies, General Chemistry, Social Work, Developmental Biology, Philosophy, Experimental Psychology, History of Social Sciences, Behavioral, Science \& Comparative Psychology, International Relations, Psychoanalysis, Social Sciences Methods, Aerospace \& Aeronautics, Human Factors, Developmental \& Child Psychology, Applied Ethics, Anthropology, General Psychology \& Cognitive Sciences, Social Psychology, Religions \& Theology, Physiology, Literary Studies, Music, Clinical Psychology, Optics, History).

\subsection{Top-Cited Greek Scientists Across Different Fields}

Thirty-two Greek scientists were among the top 15 of their scientific subfield based on a citation indicator excluding self-citations (Table 3). Almost all of them (30/32, 94\%) were listed by Scopus with an affiliation outside of Greece. Of the 32 scientists, information on place of birth could be found on 28 (except for Terzopoulos, Stamatakis, Pavlou, and Argyropoulos); three were born in Cyprus (Nicolaides, Nicolaou, Kalogirou), three were born in the United States (loannidis, Joannopoulos, Alivisatos), one was born in the United Kingdom (Lyketsos), and the remaining 21 had been born in Greece. Of the 32, 18 had received their first degree from an institution in Greece.

\section{DISCUSSION}

We have created and validated a database of scientists of Greek origin that may be helpful for evaluation, planning, and research policy purposes. It may also serve as a template for similar efforts to be undertaken for other countries to map their scientific workforce. The iterative approach that we followed may also have special added value for countries that have sustained heavy brain drain and/or that have a substantial scientific diaspora. The sensitivity and specificity achieved from such an approach in constructing scientist databases from different countries may vary depending on how unique first and last names are to geographic origin.

Our approach has tried to identify scientists originating from Greece regardless of their present or past affiliations. We have also probed the sensitivity and specificity of the database membership. The database is dependent on Scopus coverage, so scientists in fields not well covered by Scopus may be particularly underrepresented. The database includes close to 64,000 author ID files representing scientists who have published at least five papers. Given that some scientists have their publications split in more than one file, the database probably includes close to 60,000 unique scientists. Validation exercises suggest that it probably misses very few scientists who meet the productivity eligibility criteria and who have an affiliation in a Greek institution. Conversely, a more substantial proportion has been missed among those who have an affiliation in an institution outside of Greece. The estimate of the missingness in this regard varies according to different validation sets that we used. Based on scientists working abroad who on their own initiative offered to be included in a database of Greek scientists, about one in four scientists were missed with our approach. The percentage of missingness was higher based on a Wikipedia list of diasporeans, and even more when extending beyond first-generation emigrants. It is unavoidable that our approach would miss Greeks who acquire non-Greek names (upon second and subsequent generations) and for people who change their names (e.g., through marriage, by making the name less foreign-sounding in their 
new country, or other reasons) and those who have a Greek last name that was not among the ones we searched for. Some of these individuals may still be captured if they possess a highly Greek-specific first name among the list of first names that we screened for. Therefore, even though scientists with an affiliation in Greece were a slight majority in the compiled database, Greek origin scientists with an affiliation outside of Greece would probably be the majority if all Greek origin scientists could have been retrieved. The total of Greek origin scientists meeting the productivity eligibility criteria may be in the range of $80,000-100,000(\sim 1.00-1.25 \%$ of the global total). Conversely, a few scientists are included in the database by failed disambiguation. The validation process suggests that this situation is probably very uncommon.

The database reflects the large extent of general emigration from Greece as well as the massive brain drain that the country has sustained over the years, with accelerated rates in the last decade in conjunction with the economic crisis that hit Greece worse than almost any other highly developed country. We noted that the cohort of scientists with affiliation outside of Greece had on average younger publication ages, as revealed by the year of their first paper; half of them published their first paper in 2004 or more recently.

While citation indicators are quite high for the entire database averages, scientists with an affiliation outside of Greece have substantially stronger citation indicators and higher rankings in their fields compared with scientists with affiliation in Greece. The difference is more prominent among top-cited scientists, where $86 \%$ of the Greek origin scientists who are in the top $0.1 \%$ of their subfield are not in Greece. Similarly, almost all (94\%) of the Greek origin scientists who are among the top 15 of their subfield are not in Greece. Of interest, is that the large majority of these extremely highly cited scientists were born in Greece, and the majority also received their first degree in Greece. This further demonstrates the power of the brain drain process. At the same time, scientists who have remained in Greece still include large numbers placed in the top $20 \%$ of their subfield. Thus, the local scientific workforce still has considerable capacity for excellence. Of note, given our search strategy, is that our database has practically $100 \%$ sensitivity for Greek scientists abroad who are in the top $2 \%$ of citation impact, while several scientists with lesser impact may have been missed.

The database includes scientists scattered across almost every scientific subfield. Scientists with an affiliation in Greece have stronger concentrations than those with affiliations outside of Greece in many fields of clinical medicine, several fields of biology, and agriculture/ fisheries/forestry. Greece has one of the highest rates of physicians per population in the world, if not the highest (country-level data on medical doctors per 10,000 population are available at https://www.who.int/data/gho/data/indicators/indicator-details/GHO/medical -doctors-per-10-000-population). Many of them are engaged in research, authoring or coauthoring papers, as scientific publications are requested and appraised not only for academic track positions, but even for regular clinical positions in the national health system. The advantage is that these incentives create a large pool of physicians with exposure to research. The disadvantage is that much of this research may not be of high quality and these authors have no lasting commitment to research. The concentration in subfields of agriculture, fisheries, and biology is probably explained by the nature of the economy, although agriculture and related fields have shrunk in latest years. Conversely, there are several other fields where most scientists of Greek origin do not work in Greece. This pattern is particularly strong in the social and economic sciences and some cutting-edge biomedical sciences, such as developmental biology.

Some limitations need to be discussed. First, as we have already acknowledged, the database is still missing several Greek origin scientists, in particular among those living and 
working abroad. We encourage people to provide relevant information at www.drosatos.com /greekscientists to bring such cases to our attention. While it is impossible to update the database by adding one more scientist at a time, collecting information on missing individuals may allow us to consider further optimized automated processes in the future. While this paper was in peer review, and as of March 20, 2021, 13 additional names of Greek scientists were provided to us, but seven of those were already included in the database, two had fewer than five papers by early 2020, and only four had been missed (Anna-Bettina Haidich [Aristotle U Thessaloniki, $h=29$ ], Elias Franses [Purdue, $h=36$ ], losif Koutagiar [Hygheia Hospital, $h=9$ ], and Christos Chinopoulos [Semmelweis Egyetem, $h=31$ ]).

Second, the constructed database was restricted to scientists with at least five full papers. In the entire Scopus database, roughly four-fifths of author ID files have fewer than five papers. Some of the author ID files with sparse papers may be split-off fragments of the publication corpus of authors represented by some larger file. Nevertheless, by extrapolation, the total number of Greek authors who have published at least one paper may be in the range of $250,000-500,000$. The overwhelming majority of authors of 1-4 papers are not major contributors or leaders in the scientific enterprise. However, many young scientists in this group may become major contributors or leaders in the future. Therefore, follow-up updates would be useful to perform.

Third, errors (either splitting the same author into two or more author ID files or including some papers by two or more authors in the same file) and inaccuracies in affiliations are possible. Authors who recognize errors should contact Scopus directly to make these corrections in Scopus itself, so that they may be carried over in our database with any potential future updates. The entire Scopus database currently has overall 98.1\% precision (proportion of papers in an author ID file that belong to the author) and $94.4 \%$ recall (proportion of papers of an author included in the largest profile) (Baas et al., 2020). Precision and recall may be even better for Greek-name authors, because Greek names are more rare and thus more specific than those of most other origins (e.g., the disambiguation challenges for "Liu Wang" are greater than for "Yiannis Triantafyllou"). We found $8.5 \%$ of the authors in the database to have a split profile and, given that even when one profile carries the large majority of the author's papers, recall probably substantially exceeds $94.4 \%$ for our database.

Fourth, allocation of fields and subfields follows a well-established classification, but some scientists may have an almost equal number of papers in two or more fields, and the most common one may not fully capture their expertise. Their ranking would have been different had they been classified in a different subfield. Moreover, even within the same subfield, there are granular subsections with different citation densities.

Fifth, allocation of affiliation and country is performed automatically by Scopus picking just one affiliation from the most recent papers of each author. Some authors have multiple current affiliations, and some may have changed their affiliation recently. Again, we encourage authors who want to change their listed affiliation to communicate directly with Scopus. Misclassification may affect some authors in their classification as being in Greece versus outside of Greece. However, it would have been extremely difficult to curate affiliations manually and it is impossible for an outsider to know which of many affiliations an author may prefer.

Sixth, our database does not automatically distinguish between first, second, and higher generation emigrants. If deemed desirable, this would have to be done manually, and it may have implications for policy (not losing scientists versus attracting scientists). Second and higher generation emigrants are not necessarily a sign of brain drain, as they did not emigrate themselves. 
Finally, all citation metrics have limitations and they should be used with caution and not as absolute indicators (Hicks, Wouters et al., 2015; Waltman, 2016; Wang, Veugelers, \& Stephan, 2017). We made no effort to assess the quality of the published works. Some authors may rank high, but may have other reasons for concern (e.g., retracted papers, or implausibly high self-citation metrics or evidence for citation farms). These need to be carefully scrutinized on a case-by-case basis.

Acknowledging these caveats, the compiled database offers a tool that may be useful for both research and policy purposes. For a country that is trying to recover from a lengthy economic crisis and a superimposed crisis from the recent COVID-19 pandemic, realization of its scientific potential, deceleration and reversal of the brain drain and informed decision-making in the interface of science and society may offer substantial added value. The brain drain and diaspora do not need to have negative consequences for the home country; mapping of the scientific workforce and diaspora may help to maximize positive impact (Davenport, 2004; Wagner \& Jonkers, 2017).

We also hope that the iterative approach used here may be applied also to map the scientific workforce and scientific diaspora of other countries/nations as well. Scopus data can readily identify scientists with affiliation in a given country. In the case of Greece, where few scientists immigrate to from other countries, almost all scientists with affiliation in Greece have Greek names. This would not be true for countries that attract many scientists from other countries, but usually it is more important to map the entire scientific workforce rather than just native scientists. The ability to map the diaspora of different countries depends on whether there are many first and last names that are country-specific. Specificity may vary substantially across countries and careful validation and cross-checking procedures should be applied accordingly.

\section{AUTHOR CONTRIBUTIONS}

John P. A. Ioannidis: Conceptualization, Formal analysis, Investigation, Methodology, Project administration, Supervision, Validation, Visualization, Writing-Original draft, WritingReview \& editing. Chara Koutsioumpa: Data curation, Investigation, Validation, WritingReview \& editing. Angeliki Vakka: Data curation, Investigation, Validation, Writing—Review \& editing. Georgios Agoranos: Data curation, Investigation, Validation, Writing-Review \& editing. Chrysanthi Mantsiou: Data curation, Investigation, Validation, Writing—Review \& editing. Maria Kyriaki Drekolia: Data curation, Investigation, Validation, Writing—Review \& editing. Nikos Avramidis: Data curation, Investigation, Validation, Writing—Review \& editing. Despina G. Contopoulos-Ioannidis: Data curation, Formal analysis, Investigation, Validation, Visualization, Writing—-Review \& editing. Konstantinos Drosatos: Conceptualization, Data curation, Investigation, Project administration, Supervision, Validation, Writing—Review \& editing. Jeroen Baas: Conceptualization, Data curation, Formal analysis, Investigation, Methodology, Resources, Software, Validation, Writing—Review \& editing.

\section{COMPETING INTERESTS}

Jeroen Baas is an employee of Elsevier, which runs Scopus.

\section{FUNDING INFORMATION}

No funding has been received for this research.

\section{DATA AVAILABILITY}

All the data on the 63,951 scientists are available in Mendeley at https://doi.org/10.17632 /zbyctscmbn.1. 


\section{REFERENCES}

Archambault, É., Beauchesne, O. H., \& Caruso, J. (2011). Towards a multilingual, comprehensive and open scientific journal ontology. Proceedings of the 13th International Conference of the International Society for Scientometrics and Informetrics (ISSI), pp. 66-77. Durban, South Africa.

Baas, J., Schotten, M., Plume, A., Côté, G., \& Karimi, R. (2020). Scopus as a curated, high-quality bibliometric data source for academic research in quantitative science studies. Quantitative Science Studies, 1, 377-386. https://doi.org/10.1162/qss_a_00019

Davenport, S. (2004). Panic and panacea: Brain drain and science and technology human capital policy. Research Policy, 33, 617-630. https://doi.org/10.1016/j.respol.2004.01.006

Doria Arrieta, O. A., Pammolli, F., \& Petersen, A. M. (2017). Quantifying the negative impact of brain drain on the integration of European science. Science Advances, 3, e1602232. https://doi .org/10.1126/sciadv.1602232, PubMed: 28439544

Halevi, G., Moed, H. F., \& Bar-Ilan, J. (2016). Researchers' mobility, productivity and impact: Case of top producing authors in seven disciplines. Publishing Research Quarterly, 32, 22-37. https://doi .org/10.1007/s12109-015-9437-0

Hicks, D., Wouters, P., Waltman, L., de Rijcke, S., \& Rafols, I. (2015). Bibliometrics: The Leiden Manifesto for research metrics. Nature, 520, 429-431. https://doi.org/10.1038/520429a, PubMed: 25903611

Ifanti, A. A., Argyriou, A. A., Kalofonou, F. H., \& Kalofonos, H. P. (2014). Physicians' brain drain in Greece: A perspective on the reasons why and how to address it. Health Policy, 117, 210-215. https://doi.org/10.1016/j.healthpol.2014.03.014, PubMed: 24794987

Ioannidis, J. P. (2004). Global estimates of high-level brain drain and deficit. FASEB Journal, 18, 936-939. https://doi.org/10.1096/fj.03 -1394lfe, PubMed: 15173104

loannidis, J. P., Baas, J., Klavans, R., \& Boyack, K. W. (2019). A standardized citation metrics author database annotated for scientific field. PLoS Biology, 17, e3000384. https://doi.org/10.1371 /journal.pbio.3000384, PubMed: 31404057

Ioannidis, J. P. A., Boyack, K. W., \& Baas, J. (2020). Updated science-wide author databases of standardized citation indicators. PLOS Biology, 18, e3000918. https://doi.org/10.1371/journal pbio.3000918, PubMed: 33064726

Moed, H. F. (2008). UK Research Assessment Exercises: Informed judgments on research quality or quantity? Scientometrics, 74, 153-161. https://doi.org/10.1007/s11192-008-0108-1

Moris, D., Karachaliou, G. S., \& Kontos, M. (2017) Residency training in Greece: Job dissatisfaction paves the way to brain drain. Annals of Translational Medicine, 5, 123. https://doi.org/10.21037/atm 2017.03.03, PubMed: 28361088

Petersen, A. M. (2018). Multiscale impact of researcher mobility. Journal of The Royal Society Interface, 15(146), 20180580. https://doi.org/10.1098/rsif.2018.0580, PubMed: 30257927

Rijcke, S., Wouters, P. F., Rushforth, A. D., Franssen, T. P., \& Hammarfelt, B. (2016). Evaluation practices and effects of indicator use-A literature review. Research Evaluation, 25, 161-169. https://doi.org/10.1093/reseval/rvv038

Robinson-Garcia, N., Sugimoto, C. R., Murray, D., Yegros-Yegros, A. Larivière, V., \& Costas, R. (2019). The many faces of mobility: Using bibliometric data to measure the movement of scientists. Journal of Informetrics, 13, 50-63. https://doi.org/10.1016/j.joi.2018.11.002

Stark, O., Helmenstein, C., \& Prskawetz, A. (1997). A brain gain with a brain drain. Economics Letters, 55, 227-234. https://doi.org/10 1016/S0165-1765(97)00085-2

Theodoropoulos, D., Kyridis, A., Zagkos, C., \& Konstantinidou, Z. (2014). "Brain Drain" phenomenon in Greece: Young Greek scientists on their way to immigration, in an era of "crisis." Attitudes, opinions and beliefs towards the prospect of migration. Journal of Education and Human Development, 3, 229-248. https://doi.org /10.15640/jehd.v3n4a21

Trachana, V. (2013). Austerity-led brain drain is killing Greek science. Nature, 496, 271. https://doi.org/10.1038/496271a, PubMed: 23598305

Veugelers, R. (2017). Countering European brain drain. Science, 356(6339), 695-696. https://doi.org/10.1126/science.aan3920, PubMed: 28522487

Wagner, C., \& Jonkers, K. (2017). Open countries have strong science. Nature, 550, 32-33. https://doi.org/10.1038/550032a, PubMed: 28980660

Waltman, L. (2016). A review of the literature on citation impact indicators. Journal of Informetrics, 10, 365-391. https://doi.org /10.1016/j.joi.2016.02.007

Wang, J., Veugelers, R., Stephan, P. (2017). Bias against novelty in science: A cautionary tale for users of bibliometric indicators. Research Policy, 46, 1416-1436. https://doi.org/10.1016/j .respol.2017.06.006

Yurte, T. (2017). An analysis of the foreign-educated elite academics in the United States. Journal of Informetrics, 11, 358-370. https:// doi.org/10.1016/j.joi.2017.02.008

Zhang, X., Zhao, J., \& LeCun, Y. (2015) Character-level convolutional networks for text classification. In Proceedings of the 28th International Conference on Neural Information Processing Systems (Vol. 1, pp. 649-657). 